\title{
Pioneering Spirit Demanded
}

Dear Reader,

Although 2015 saw a total of 12,363 electric vehicles registered, admittedly more than 2014, the proportion of all registrations remains modest at barely $0.4 \%$. Even if you add the 33,630 newly registered hybrid vehicles to the total, the share still only comprises around $1.4 \%$ of the 3.2 million newly registered vehicles. Along with the long transition phase toward electromobility, this reaffirms the importance of accelerating efforts to boost combustion engine efficiency. The International Engine Congress, held in BadenBaden at the end of February, showcased interesting advances in this field. Developers continue to break new ground in injection and combustion technology, leading us into a phase of intensifying competition between electrification and combustion engines pushed to their limits.

Investing in the development of more efficient engines also means focusing on fuel. Greenhouse gas emissions in the transport sector can be reduced by substituting fossil fuels with $\mathrm{CO}_{2}$-neutral alternatives. Unfortunately, however, most of the latter remain in the trial phase. From an efficiency perspective, of course, having a 100-\% electric engine in the chain is by far the best option and indeed a must whenever local efforts to target zero emissions are being made. Looking at the bigger picture of mobility, however, and the overall energy industry, PtL and PtG will remain relevant as we move closer toward $\mathrm{CO}_{2}$-neutral resources, if only for storage reasons.

Another possible and promising future development is the move toward synthetic fuels - oxygenates - which include an oxygen component. From an abstract perspective, the ideal fuel of the future would have less carbon, less hydrogen and more oxygen than at present. RWTH Aachen University has identified a further two alternative fuels in the form of 2-methylfuran and 2-butanone for use in supercharged gasoline engines, the thermodynamic benefits of which were described in the MTZextra special issue "Fuel and Lubricants of the Future".

In actual fact, the key fuel question relates not to technology but rather to how to create a feasible business model given the amount of investment required. This demands a pioneering spirit, not tactical dallying. This belief is also what comes through in an interview with Michael Bargende and Stefan Pischinger on page 22: it has long since been time for decisive progress in the field of synthetic fuels.

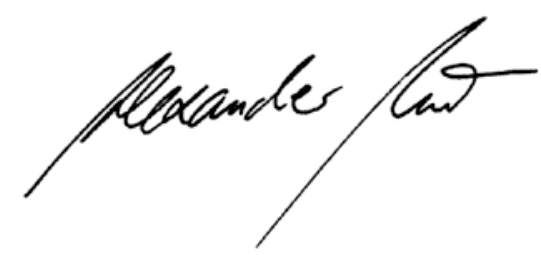

Dr. Alexander Heintzel

Editor in Chief

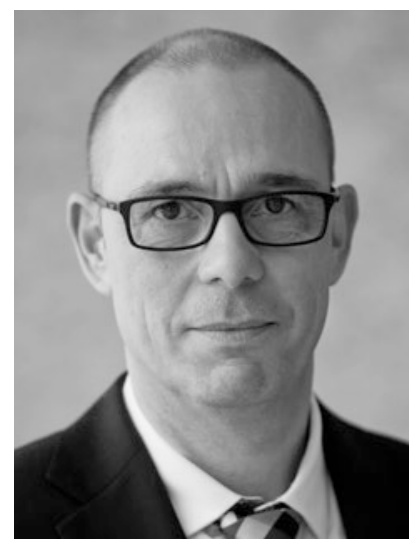

